NBER WORKING PAPER SERIES

\title{
THE IMPACT OF STATE PHYSICAL EDUCATION REQUIREMENTS ON YOUTH PHYSICAL ACTIVITY AND OVERWEIGHT
}

\author{
John Cawley \\ Chad Meyerhoefer \\ David Newhouse \\ Working Paper 11411 \\ http://www.nber.org/papers/w11411
NATIONAL BUREAU OF ECONOMIC RESEARCH
1050 Massachusetts Avenue
Cambridge, MA 02138
June 2005

Corresponding author: John Cawley, Department of Policy Analysis and Management, 134 MVR Hall, Cornell University, Ithaca NY 14853 Email: JHC38@ cornell.edu We thank Joe Newhouse and Dean Lillard for helpful comments, Pauline Ippolito for encouragement, and Marie Tansioco for research assistance. The views expressed are those of the authors, and no official endorsement by the Agency for Healthcare Research and Quality and the Department of Health and Human Services, or the International Monetary Fund, its Executive Board, or its management is intended or should be inferred. The views expressed herein are those of the author(s) and do not necessarily reflect the views of the National Bureau of Economic Research.

(C2005 by John Cawley, Chad Meyerhoefer, and David Newhouse. All rights reserved. Short sections of text, not to exceed two paragraphs, may be quoted without explicit permission provided that full credit, including (C) notice, is given to the source. 
The Impact of State Physical Education Requirements on Youth Physical Activity and Overweight John Cawley, Chad Meyerhoefer, and David Newhouse

NBER Working Paper No. 11411

June 2005

JEL No. I1, I2

\begin{abstract}
To combat childhood overweight, which has risen dramatically in the past three decades, many medical and public health organizations have called for students to spend more time in physical education (PE) classes. This paper is the first to exploit state PE requirements as quasi-natural experiments in order to estimate the causal impact of PE on student activity and weight. We study nationwide data from the YRBSS for 1999, 2001, and 2003 merged with data on state minimum PE requirements from the 1994 and 2000 School Health Policies and Programs Study and the 2001 Shape of the Nation Report.
\end{abstract}

We find that certain state regulations are effective in raising the number of minutes during which students are active in PE. Our results also indicate that additional PE time raises the number of days per week that students report having exercised or engaged in strength-building activities, but lowers the number of days in which students report light physical activity. PE time has no detectable impact on youth BMI or the probability that a student is overweight. We conclude that while raising PE requirements may make students more active by some (but not all) measures, there is not yet the scientific base to declare raising PE requirements an anti-obesity initiative.

John Cawley

Department of Policy Analysis and Management Cornell University

134 MVR Hall

Ithaca, NY 14853

and NBER

jhc38@cornell.edu

Chad D. Meyerhoefer

Agency for Healthcare Research and Quality

540 Gaither Road

Rockville, MD 20850

cmeyerhoe@ahrq.gov
David Newhouse

Poverty and Social Impact Analysis Group

Fiscal Affairs Department

International Monetary Fund

$70019^{\text {th }}$ St., NW

Washington, DC 20431

dnewhouse@imf.org 


\section{Introduction}

Over the past three decades the prevalence of overweight among American youth has risen dramatically. The Centers for Disease Control and Prevention define childhood overweight as a body mass index ${ }^{2}$ (BMI) above the 95th percentile for children of the same age and gender (benchmarked against the historic BMI distribution). ${ }^{3}$ Since 1970 , the fraction overweight has almost quadrupled among children aged 6-11 years and more than doubled among adolescents aged 12-19 years (Ogden et al., 2002). The prevalence of overweight among American children is now considered to be epidemic (U.S. DHHS, 2001; IOM, 2004). As of 1999-2002, 16 percent of children aged 6-19 are clinically overweight, a figure three times greater than the Healthy People $2010^{4}$ goal of 5 percent (Hedley et al., 2004, U.S. DHHS, 2000, IOM, 2004). The increasing prevalence of overweight children is a major public health concern because of its implications for physical health (Ebbeling, Pawlak, and Ludwig, 2002; Kimm and Obarzanek, 2002), mental health (Puhl and Brownell, 2002; Strauss, 2000), and medical care costs (Wang and Dietz, 2002).

One factor that may have contributed to overweight among children is decreased physical education (PE) in schools. The percentage of high school students enrolled in daily PE classes declined from 41.6 percent in 1991 to 28.4 percent in 2003 (Grunbaum et al., 2004). Over that period, school minimum PE requirements generally decreased. Between 1994 and 2000, the percentage of middle and junior high schools that required

\footnotetext{
${ }^{2}$ Body mass index (BMI) is calculated as weight in kilograms divided by height in meters squared.

${ }^{3}$ The highest weight classification for adults is "obese" but in order to avoid stigmatizing youth with that label, the highest weight classification for children is "overweight."

${ }^{4}$ Healthy People 2010 states U.S. national health objectives, identifies the most significant preventable threats to health, and establishes national goals to reduce these threats by the year 2010 (U.S. DHHS, 2000).
} 
daily PE fell from 17 percent to 6.4 percent (Burgeson et al., 2001; U.S. DHHS, 2000).

However, the percentage of senior high schools that required daily PE rose from 2 percent to 5.8 percent over the same period (Ibid).

In the wake of the concurrent trends of rising overweight and declining PE time, many medical, public health, and education organizations have called for students to spend more time in PE classes. For example, the following organizations have called for increasing the amount of PE so that all American youth participate in it daily: the President's Council on Physical Fitness and Sports (PCPFS, 2001), the Secretaries of Health and Human Services and Education (U.S. DHHS and U.S. DOE, 2000), Healthy People 2010 (U.S. DHHS, 2000), the National Association of State Boards of Education (NASBE, 2000), the National Association for Sport and Physical Education (NASPE, 2004), and the American Academy of Pediatrics (AAP, 2000). ${ }^{5}$ Policymakers have responded; in 2005, 38 state legislatures have introduced legislation to increase or reform school physical education (Plaza, 2005). If increased PE does not reduce student weight or reduce the probability of overweight, these calls and efforts to increase PE time may not represent the most efficient use of school finances or student time.

Several studies confirm that specific variations on PE curricula can increase student physical activity (Kahn et al., 2002; Trudeau and Shephard, 2005; Task Force on Community Preventive Services, 2001). However, despite the number of organizations calling for increased PE to reduce student overweight, there is little evidence that PE

\footnotetext{
${ }^{5}$ Some of the organizations calling for greater PE qualify their recommendation by stating that there should be an increase in "quality" PE, implying that without the proper curriculum, additional PE time may not have much effect. In this paper, we estimate the impact of raising the amount of time that students must spend in PE but our data do not allow us to estimate the impact of raising the "quality" of PE. Thus, our results reflect the impact of $\mathrm{PE}$ on physical activity and weight for the average quality of PE in our sample (which is unobserved). One observed measure of PE quality - the prevalence of being physically active during PE class - did not change significantly between 1991 and 2003 (Lowry et al., 2004).
} 
lowers weight or decreases the risk of overweight (Kahn et al., 2002; IOM, 2004). There are three main reasons for uncertainty about the impact of higher PE requirements. First, schools may fail to comply with state regulations. It is estimated that 26 percent of PE classes in the U.S. fail to comply with official requirements (Hardman and Marshall, 2000). Second, PE classes may do little to promote exercise. PE classes have been criticized for taking a "Roll out the balls and let them play" approach, in which there is no organized activity and no assurance that each student is physically active (U.S. DHHS and U.S. DOE, 2000). One study calculated that students are moderately to vigorously active only 8.6 percent of the time during PE - which works out to 3.4 minutes per 40minute class (Simons-Morton et al., 1993). Finally, there is no guarantee that more physical activity in PE will ultimately reduce children's weight. The extent to which children respond to increased PE exercise by reducing outside exercise or increasing caloric consumption is unknown. For these reasons, increasing the time that kids spend in PE may have little impact on their weight.

Several randomized interventions to alter PE have been conducted (Kahn et al., 2002); however, the purpose of these interventions was not to measure the impact of additional PE but to evaluate the effectiveness of innovative PE curricula (Datar and Sturm, 2004). As a result, there is little evidence as to whether more PE as it currently exists impacts physical activity or weight. The best available evidence is based on the change in weight associated with a change in PE for kindergarten and first grade students in the Early Childhood Longitudinal Study, which finds that additional PE is associated with lower BMI among heavier girls, but no change in BMI for lighter girls or for heavier or lighter boys (Datar and Sturm, 2004). This paper builds on Datar and Sturm (2004) in 
several ways. First, we study high school students, who have rarely been studied in this context (Kahn et al., 2002). Second, we study a sample that is three times larger, which allows more precise estimates. Finally, and most importantly, we focus on the effect of state laws. Specifically, we study the extent to which state laws promote PE time and have an impact on outcomes of interest like physical activity and weight. State laws also provide a plausibly exogenous source of variation in PE time, which we exploit to estimate the effect of PE on weight.

\section{Methods}

If the amount of time that students spend in PE was exogenous and uncorrelated with unobserved local socioeconomic status, then an OLS regression of physical activity or weight on PE time would produce a consistent estimate of the impact of PE on those outcomes. However, those assumptions are unrealistic. First, PE classes may be electives and students with a preference for exercise may be more likely to opt to take PE. This selection may generate a correlation between PE time and physical activity and weight even if PE time does not causally affect physical activity or weight. Second, the quality and finances of the school may partly determine the number of PE classes offered. It is possible that wealthier school districts offer more PE because they can afford to offer more of everything, but it is also possible that wealthier school districts may reduce PE to devote more time to college preparatory courses. Either way, there may be omitted variable bias if socioeconomic characteristics are correlated with student overweight, and it is difficult to know in which direction the bias operates. ${ }^{6}$ Finally, schools and districts

\footnotetext{
${ }^{6}$ Sobal and Stunkard (1989) review 144 studies and conclude that, in developed countries, the relationship between SES and obesity is inconsistent for children.
} 
may raise PE requirements in response to high obesity rates. Consistent with this, we find in the Youth Risk Behavior Surveillance System (YRBSS) that the average PE minutes per week is 68 for overweight students, 66 for students at risk of overweight, and 64 for healthy-weight students.

Simple OLS regressions will also understate the magnitude of the effect of PE time on physical activity and weight if PE time is reported with error. If a student's misreporting of PE time is unrelated to a student's weight, the estimated OLS coefficient on PE time will be biased towards zero.

We use the method of instrumental variables to generate a consistent estimate of the impact of additional PE time on student physical activity and body weight in the presence of endogeneity and measurement error. Specifically, we treat state laws mandating minimal PE requirements as quasi-natural experiments. The first possible reason for bias in OLS estimates is that students have discretion about how many PE classes to enroll in; the IV method addresses this problem by studying variation in PE that is beyond the students' control - that which is due to state laws. The second possible reason for bias in OLS is that school-level policies may be correlated with local SES and therefore student weight. Although state regulations may be correlated with state SES, their use is an improvement because we are able to control directly for state SES using state per capita income, education levels, and participation in the National School Lunch Program (NSLP). ${ }^{7}$ Our identifying assumption is that the state laws mandating PE time are independent of unobserved determinants of obesity after controlling for student observables as well as state income, education, and school lunch program participation.

\footnotetext{
${ }^{7}$ The NSLP data also serves as a partial control for the nutritional quality of school meals, since school cafeterias participating in the program must meet certain nutritional standards that non-participants do not.
} 
This assumption is discussed in greater detail below. The final advantage of IV is that it eliminates the influence of measurement error in student reports of PE time.

\section{Data}

Our models are estimated using the 1999, 2001, and 2003 Youth Risk Behavior Surveillance System (YRBSS) merged with state PE requirements collected in the 1994 and 2000 School Health Policies and Programs Study (SHPPS) and the 2001 Shape of the Nation Report (SONR). Summary statistics for all variables used in our models are provided in Appendix Table 1.

\section{Youth Risk Behavior Surveillance System (YRBSS)}

The YRBSS is a nationally representative survey of high school students (grades 9-12) that was established by the Centers for Disease Control and Prevention to monitor the prevalence of risky youth behaviors, including those relating to physical activity and obesity. The YRBSS has been conducted biennially since 1991. We pool YRBSS data from the 1999, 2001, and 2003 surveys; each of these collected data on participation in PE classes, physical activity, weight, and height. ${ }^{8}$ YRBSS surveys prior to 1999 did not record weight or height. The wording of the questions used to create our key variables on PE participation, physical activity, and weight is provided in the Appendix. State PE regulations were matched to respondents using the state identifiers that are available in the restricted-use version of the YRBSS data. Other annual state-level variables were matched with the YRBSS in the same manner, including state per capita income (obtained form the U.S. Department of Commerce, Bureau of Economic Analysis), the

\footnotetext{
${ }^{8}$ An error in the way in which height was recorded for Arkansas respondents in 2003 has led the CDC to release a revised version of the data with height and weight for most Arkansas respondents set to missing. We use the revised version of the 2003 data.
} 
percentage of the state population with a bachelor's degree or higher (obtained from the U.S. Census Bureau, Population Division), and the percentage of the state's children participating in the NSLP (obtained from the U.S. Department of Agriculture, Food and Nutrition Service).

The YRBSS uses a three-stage cluster sample design to obtain a nationally representative sample of high school students in the U.S. (Brener et al., 2004). We apply STATA's svy commands to the YRBSS variables on strata, primary sampling unit, and sample weight to produce estimates that can be generalized to the population of American youth. ${ }^{9}$ In 1999, 2001, and 2003, the response rate of schools and students were each roughly 80 percent, resulting in an overall response rate of roughly two-thirds. Total sample sizes are 15,349 in 1999, 13,601 in 2001, and 15,214 in 2003; the pooled sample consists of 44,164 students. Observations were dropped if height, weight, or PE time were not recorded. This reduced the total pooled sample by $16 \%$ to 36,888 students. ${ }^{10}$

In the YRBSS, PE time is self-reported in two questions: the first asks the number of days per week that the student has PE class, and the second asks the number of minutes per class that the child is actually active (see the Appendix for the complete language of these questions). Since the latter question asks students to report minutes in one of several intervals, we multiply the number of days per week the student has PE

\footnotetext{
${ }^{9}$ In some cases svy commands are not available for the estimation routine we employ, only survey weight and cluster corrections. However, in the linear regression case the two estimation approaches produce nearly identical results.

${ }^{10}$ In order to assess the impact of attrition on the estimating sample, we compare the means of several demographic variables and proxies for SES. Those dropped from the sample due to item non-response are a higher percentage black or Asian and from urban areas, and a lower percentage from the Midwest and in grade 12 than those in the estimating sample. In addition, the proxy variables measuring levels of school and domestic violence and access to medical care suggest the omitted students have lower SES on average than the estimating sample. A table of mean characteristics of the estimation sample and excluded observations is available upon request.
} 
class by the lower bound of the interval to derive total active time in PE class per week. ${ }^{11}$ Therefore, our measure on PE minutes per week is a conservative estimate of the amount of time students actually spent exercising in PE class, which will lead to upward bias in the coefficient on PE minutes. In general, reported active time in PE class is very low, with an average reported level of 13 minutes per day and only 2 minutes per day for the median student. This is primarily due to the fact that many school districts only offer or require PE for one or two years of high school.

Our three outcome measures for physical activity are those chosen by the CDC to monitor progress toward Healthy People 2010 goals: the number of days per week in which the student exercises for 20 minutes or more, the number of days per week in which the student engages in strength-building activity, and the number of days per week in which the student engages in light activity for 30 minutes or more; the full text of the questions is listed in the Appendix. Note that these questions cover all exercise and activity, whether in or out of PE class; we are interested in the impact of PE on total activity. There are other measures of physical activity that are meaningful and of interest, but these are the ones that the CDC has chosen to track and use to measure progress toward Healthy People 2010 goals and for that reason they are our focus.

We study two outcomes concerning student weight. The first is a linear measure of weight: body mass index. The second is clinical weight classification; we examine both an indicator for overweight (defined as a BMI greater than or equal to the historic

\footnotetext{
${ }^{11}$ For the interval "Less than 10 minutes" we assume active time was 5 minutes. The top category in the 1999 YRBSS is "more than 30 minutes" while the 2001 and 2003 YRBSS also included the following categories: 31 to 40,41 to 50, 51 to 60 , and more than 60 minutes. To ensure uniformity across years, we assign the lower bound of the top interval in 1999 (31 minutes) to anyone reporting more than 30 minutes in 2001 or 2003. As a sensitivity check, we used the proportions reporting in the upper categories in 2001 and 2003 to estimate the distribution of minutes in the top category in 1999 and found very similar results. Using the midpoint instead of the lower bound of each interval also did not appreciably impact the results.
} 
$95^{\text {th }}$ percentile of age and gender specific weight-for-height) and an indicator for at risk of overweight (defined as a BMI greater than or equal to the historic $85^{\text {th }}$ percentile of age and gender specific weight-for-height).

Weight and height are self-reported in the YRBSS and are likely reported with error. The nature of this reporting error in the YRBSS is unknown, because the true BMI of YRBSS respondents is not observed. To determine the extent of reporting error in weight among high school students, researchers at the CDC surveyed high school students and collected data on both self-reported and measured weight and height (Brener et al., 2003). They found that self-reported values of height, weight, and BMI were highly correlated with their measured values. The correlation coefficient for self-reported and measured weight was 0.93 , that for self-reported and measured height was 0.90 , and that for BMI constructed using self-reports and measurements was 0.89 . The average student overreported height by 2.7 inches and underreported weight by 3.5 pounds, resulting in an underreported BMI by 2.6 units. Brener et al. (2003) conclude that selfreported height and weight by high school students are valid proxies for measured values, and that the use of self-reports of height and weight leads to underestimates of the prevalence of overweight. In the National Health and Nutrition Surveys (NHANES) data for adults, measurement error is negatively correlated with true BMI, as obese adults tend to under-report their weight and thin adults tend to over-report their weight (Villanueva, 2001, Plankey et al, 1997). If this pattern holds for high school students as well as adults, then estimates of the effect of PE on BMI will be biased towards zero (Bound, et al, 
1999, p. 3,713). Empirically, however, the magnitude of this bias appears to be small, on the order of ten percent. ${ }^{12}$

A limitation of the YRBSS is that the CDC does not release school-level identifiers for the YRBSS so we are unable to separate private school from public school students. This is relevant because public schools are legally bound to comply with state regulations concerning physical education, but private schools are not. Although the state requirements for public schools may set a standard that is adopted by private schools, the impact of state regulations is likely to be less for private school students than public school students. Since our models are estimated with a pooled sample of public and private school students, our estimates likely underestimate the impact of state regulations on public school students.

A major strength of the YRBSS data is that the questions on weight and physical activity were expressly written to track the outcomes that policymakers care about (i.e. the Healthy People 2010 goals); this makes YRBSS arguably the most appropriate dataset to use when studying youth PE time, physical activity, and overweight.

\section{School Health Policies and Programs Study (SHPPS) and the Shape of the}

\section{Nation Report (SONR)}

The School Health Policies and Programs Study (SHPPS) is a national survey of all states and a sample of districts and schools that was conducted to assess school health policies and programs, including school PE standards and guidelines and required PE instruction for students in various grades (CDC, 2005; Burgeson et al., 2001). We use

\footnotetext{
${ }^{12}$ The attenuation bias due to non-classical measurement error is equal to one plus the coefficient from a simple regression of measurement error on true (measured) BMI. Plankey, et al (1997) report standard errors and the correlation coefficient between reporting error and measured BMI, which indicate that the coefficient is approximately -0.1 . This implies that OLS and IV coefficients are attenuated by a factor of approximately 10 percent, which is not large enough to alter any of our qualitative results.
} 
data from the first and second rounds of the SHPPS, conducted in 1994 and 2000. In both cases, state-level data were collected from all 50 states plus the District of Columbia with a response rate of $100 \%$.

The Shape of the Nation Report (SONR), conducted in 2001 by the National Association for Sport and Physical Education, is also a national survey of all states and the District of Columbia. The purpose of the SONR was to determine the mandates regarding, and availability of, physical education programs at each school level in every state. SONR also collected information on the characteristics of the PE programs, such as the qualifications of PE teachers, curricular standards, class size, and mechanisms for program accountability and student achievement. All states responded to the survey.

The SHPPS and SONR data provide us with our quasi-natural experiments: crossstate variation in minimum PE requirements. The key variable that we use from the 2001 SONR is the unit or credit requirement for high school PE coursework mandated by each state, which varies from 0 (no requirement) to 4 units. In general, one unit of PE is equivalent to a year of instruction, although the number of classroom minutes per unit varies by state. The information we use from the SHPPS data captures both levels and changes in the enforcement of these requirements. Using the 2000 SHPPS we create an indicator variable for whether the state has "adopted a policy encouraging districts or schools to follow any national or state physical education standards or guidelines”. In both the 1994 and 2000 SHPPS states are asked whether they have adopted a policy requiring schools to follow national or state physical education curriculum, guidelines, or standards. We create an indicator variable for states that required compliance with guidelines in 2000, but not 1994 in order to capture the effect of increasing state-level 
enforcement of PE standards over time. Figure 1 displays a composite measure of these three state PE regulations. It demonstrates that there is substantial variation within region in the strictness of state PE requirements, which is important because we include indicator variables for region to control for any regional correlation between the strictness of PE requirements and student outcomes.

A limitation of our instruments is that they represent a single cross-section of time. Ideally we would observe state requirements for every year we have YRBSS data (1999, 2001, and 2003) but the most recent SHPPS took place in 2000 and the SONR in 2001. Therefore, we must assume that the regulations recorded in the SHPPS and SONR remained unchanged during the period 1999 to 2003. Despite the lack of temporal variation in our instruments, they are powerful enough to meet the conventional standard for the strength of instruments $(\mathrm{F}=10)$.

\section{Empirical Results}

We first estimate the impact of state requirements on the number of minutes per week that students spend exercising in PE. Table 1 lists the results of a regression of PE minutes per week (in hundreds) on state requirements and student characteristics. In case the instruments are correlated with state socioeconomic status, we control for state per capita income, the percentage of residents with at least a bachelor's degree, and NSLP participation per capita. The regression shown in Table 1 serves as the first stage of our IV method. The F statistic on the three state requirements is 10.0, precisely the standard for instruments suggested by Staiger and Stock (1997). The coefficient on each of the three instruments is statistically significant at the 5 percent level. ${ }^{13}$ The coefficient on the

\footnotetext{
${ }^{13}$ We chose a subset of the instruments available to us in order to maximize the correlation between our instruments and active PE time. To do so, we first identified all available state-level PE policies that
} 
state PE unit/credit requirement indicates that requiring an extra unit of PE instruction raises reported active time in PE class by 6.9 minutes per week. In states that encouraged schools to comply with PE guidelines, students report an additional 15.7 minutes of PE time per week. In states that increased enforcement of curriculum guidelines after 1994, students reported 17 additional minutes of active time in PE class. In summary, state regulations of the types we examine appear to increase the time that students spend exercising during PE class.

We next test whether additional time spent exercising in PE translates into more days of physical activity. The YRBSS asks how many days out of the past seven respondents participated in three different types of physical activity: 1) at least 20 minutes of vigorous exercise 2) at least 30 minutes of light activity 3) strength building exercise (no minimum number of minutes). Since the responses are in the form of counts, we use count data regression techniques to model students’ responses. In particular, we estimate negative binomial regressions using STATA’s generalized linear modeling (glm) estimation routine. ${ }^{14}$ The results are reported in columns 1,3 , and 5 of Table 2. These regressions suggest that PE time is positively and significantly correlated with all three physical activity measures. An extra 100 minutes of PE exercise per week is associated with .94 extra days with at least 20 minutes of exercise (column 1), .73 extra days with strength-building activity (col. 3), and .38 extra days with at least 30 minutes of light activity (col. 5). ${ }^{15}$

theoretically increase active PE time but that are not directly associated with individual BMI. We then excluded instruments whose simple correlation with PE time was negative, and chose the set of instruments with the highest first stage F-statistic.

${ }^{14}$ The Poisson distribution is also commonly used to model count data, but each of the exercise measures in the YRBSS failed the test of overdispersion, necessitating the use of this more flexible distribution (Cameron and Trivedi, 1998).

${ }^{15}$ Standard errors of the marginal effects for all non-linear models were computed using the delta method. 
However, as discussed above, these estimates are likely to suffer endogeneity bias. To address this, we estimate instrumental variables negative binomial regressions using the STATA qvf procedure (Hardin, Schmiediche, and Carroll, 2003). Column 2 of Table 2 indicates that more PE exercise time raises the number of days in which students report engaging in exercise; specifically, an additional 100 minutes of PE exercise per week causes a .73 increase in the number of exercise days. Put another way, for students to spend an additional day with at least 20 minutes of exercise requires 137 additional minutes of PE exercise per week (not simply PE class time, but minutes spent actually exercising in PE), which translates into an additional 27.4 minutes of PE exercise per school day.

The fourth column of Table 2 indicates that additional PE time also raises the number of days with strength-building activity. Specifically, an extra 100 minutes spent in PE are associated with an additional .72 days with strength-building activity (which is very close to the non-IV estimate). Put another way, one additional day with strengthbuilding activity is reported for each additional 140 minutes of PE time, which translates into an additional 28 minutes of PE per school day. The large number of additional daily minutes of PE exercise necessary to generate one extra day with at least 20 minutes of exercise or one extra day with strength-building activity indicates an interesting discrepancy. It appears that little of the time spent in PE classes that students classify as spent exercising or playing sports translates into additional days with substantial exercise or strength-building activity. This suggests that the sports that students play during PE do not involve considerable exercise or strength. 
The sixth column of Table 2 indicates that additional PE exercise actually reduces the number of days in which students engage in at least 30 minutes of light activity. This is a reversal of the sign from the regression that did not use IV to address endogeneity; in that regression, 100 extra PE minutes were associated with .38 additional days of light exercise. However, in our IV model, an extra 100 minutes of PE exercise per week causes a decrease of .65 days with light activity. Put another way, one fewer day with light activity is reported for every 153 additional minutes of PE exercise (or 30.6 additional minutes of PE exercise per school day). The negative relationship between PE exercise time and light activity days may be due to offsetting behavior. That is, students may have a target amount of time they wish to spend physically active, and if they are forced to spend more time exercising in PE (as we saw in column 2) they may respond by either cutting back on discretionary light activities outside of school, or substituting vigorous exercise for light activities. It is not clear, however, why this offsetting behavior or substitution exists only for light activity and not moderate to vigorous exercise or strength-building activities.

We next test whether additional PE time affects student weight. We first use a linear measure of weight, body mass index, then we use clinical weight classifications: at risk of overweight, and overweight. The results of OLS and IV regressions for BMI are presented in Table 3. The OLS results in column 1 of Table 3 indicate a virtual zero correlation of PE time with BMI; an extra 100 minutes of PE per week are associated with a rise in BMI of 0.02 units, which for a person who is 5 feet 5 inches tall translates into one-tenth of a pound (which is not statistically significant). The results of IV models that address the endogeneity of PE time are presented in column 2. No coefficient on PE 
time is statistically significant; however, because of the large standard errors, a substantial negative effect cannot be ruled out. Specifically, the 95 percent confidence interval of the IV estimate ranges from approximately -0.80 units to 1.10 units. Nonetheless, the point estimate indicates that an extra 100 minutes of PE exercise per week are associated with a gain in BMI of 0.15 units, which for a person who is 5 feet 5 inches tall translates into nine-tenths of a pound. PE time does not have a detectable impact on student weight.

We also test whether PE exercise time is associated with a lower probability that students are overweight or at risk of overweight. Table 4 presents the results of logit and logit IV regressions; in columns 1 and 2 the dependent variable is an indicator for whether the student is clinically overweight, which is defined as a BMI greater than or equal to the historic $95^{\text {th }}$ percentile, and in columns 3 and 4 the dependent variable is an indicator for whether the student is at risk of overweight, which is defined as a BMI greater than or equal to the historic $85^{\text {th }}$ percentile. In neither OLS nor IV is the coefficient on minutes of PE exercise statistically significant in either the overweight or risk of overweight regression. In addition, the point estimates are very close to zero. In summary, PE time has no detectable impact on either BMI or weight classification.

\section{Discussion}

It has been estimated that roughly a quarter of all PE classes in the U.S. fail to comply with official requirements (Hardman and Marshall, 2000), which implies that schools may not respond to tougher state regulations concerning PE. However, our 
results suggest that certain state regulations are effective in increasing the amount of time that students are physically active in PE.

Our finding that increased PE time increases the number of days with at least 20 minutes of moderate to vigorous exercise and with strength-building activity is important because such activities have significant health benefits (U.S. DHHS, 1996). However, this is tempered by the small magnitude of these positive effects and the negative effect of PE time on the number of days students engage in 30 minutes or more light physical activity.

Our inability to detect an impact of PE on weight or the probability of overweight is consistent with previous studies that did not exploit variation in state laws or address the endogeneity of PE minutes (Kahn et al., 2002). The consistent inability to reject the null hypothesis of no effect of PE on student overweight suggests there is not yet a scientific base for the many recent calls to increase PE in order to prevent or reduce childhood overweight (by, e.g., NASPE, 2004; PCPFS, 2001; U.S. DHHS and U.S. DOE, 2000; AAP, 2000).

Even if PE leaves weight unchanged it may be valuable if it leads to muscle gain and fat loss. We sought suggestive evidence on whether increased exercise typically leads to muscle gain perfectly canceling out fat loss, leaving weight unchanged. Specifically, we compared the BMI of students who do and do not participate in team sports. We find that participation in sports teams is associated with lower BMI and a lower probability of overweight, with both measures decreasing in the number of sports teams in which the student participates. This suggests that meaningful physical activity does not lead to muscle gain perfectly canceling out fat loss leaving weight unchanged. 
Instead, it may be that some of the PE time that students classify as devoted to exercise or sport is in fact relatively sedentary. For example, we find that large increases in PE minutes per week are necessary for students to report additional days with meaningful exercise or strength-building activity. This is consistent with Simons-Morton et al. (1993), which found that children were moderately to vigorously active in PE for less than 10 percent of class time. Taken together, our results are consistent with the criticism that too often PE consists of "roll out the balls and let them play" -- unstructured and unmotivated class time involving little vigorous activity (U.S. DHHS and U.S. DOE, 2000). If this explains the weak association between PE time and physical activity, and the lack of correlation between PE time and student overweight, then improvements in PE curriculum should precede mandated increases in PE time in order to avoid inefficient use of school finances and student time.

A more difficult challenge concerns offsetting behavior: in our sample, students appear to decrease light activity in response to additional exercise during PE. Interestingly, other research suggests that the effect does not work in reverse - when PE time is curtailed, students do not respond by increasing their physical activity outside of school (Dale, Corbin, and Dale, 2000). The offsetting behavior we observe is a challenge for policymakers because even if PE curricula are strengthened to include more moderate to vigorous exercise, its effects may be cancelled out if students become more sedentary during their discretionary time; on net, weight may remain unaffected. How public health officials and educators can reduce or eliminate such offsetting behavior is a challenge for future studies. 


\section{Appendix: \\ Relevant Questions in YRBSS}

\section{Questions used to create measure of minutes of $P E$ per week:}

In an average week when you are in school, on how many days do you go to physical education (PE) class? [answers are integers from 0 to 5]

During an average physical education (PE) class, how many minutes do you spend actually exercising or playing sports? [answers are categorical: "I do not take PE", 0-10 minutes, 11-20, 21-30, 31+ (2001 and 2003 surveys have categories 31-40, 41-50, 51-60, $60+$ and the 1999 survey instead has $31+$ as its top category)]

\section{Questions used to create measures of physical activity:}

On how many of the past 7 days did you exercise or participate in a physical activity for at least 20 minutes that made you sweat and breathe hard, such as basketball, soccer, running, swimming laps, fast bicycling, fast dancing, or similar aerobic activities? [answers are integers from 0-7]

On how many of the past 7 days did you participate in physical activity for at least 30 minutes that did not make you sweat or breathe hard, such as fast walking, slow bicycling, skating, pushing a lawn mower, or mopping floors? [answers are integers from 0-7]

On how many of the past 7 days did you do exercises to strengthen or tone your muscles, such as push-ups, sit-ups, or weight lifting? [answers are integers from 0-7]

\section{Questions used to create BMI measure:}

How tall are you without your shoes on? [answers are continuous]

How much do you weigh without your shoes on? [answers are continuous] 


\section{Works Cited}

American Academy of Pediatrics. 2000. "Physical Fitness and Activity in Schools." Pediatrics, 105(5): 1156-1157.

Bound, John, Charles Brown and Nancy Mathiowetz, "Measurement Error in Survey Data,” in Heckman, James and Leamer, Edward, eds. Handbook of Econometrics, vol. 5. Amsterdam: North Holland, 1999.

Brener, Nancy D., Tim McManus, Deborah A. Galuska, Richard Lowry, and Howell Wechsler. 2003. "Reliability and Validity of Self-Reported Height and Weight Among High School Students.” Journal of Adolescent Health, 32(4): 281-287.

Brener, Nancy D. et al. 2004. "Methodology of the Youth Risk Behavior Surveillance System.” Morbidity and Mortality Weekly Report, 53(RR-12): 1-14.

Burgeson, Charlene R., Howell Wechsler, Nancy D. Brener, Judith C. Young, and Christine G. Spain. 2001. "Physical Education and Activity: Results from the School Health Policies and Programs Study 2000.” Journal of School Health, 71(7): 279-293.

Cameron, A.C. and P.K. Trivedi. 1998. Regression Analysis of Count Data. Cambridge University Press: New York, NY.

Centers for Disease Control and Prevention, Department of Health and Human Services. 2005. “Overview: School Health Policies and Program Study 2000.” World wide web content.

http://www.cdc.gov/HealthyYouth/shpps/factsheets/pdf/overview.pdf

Dale, Darren, Charles B. Corbin, and Kathleen S. Dale. 2000. "Restricting Opportunities to Be Active During School Time: Do Children Compensate by Increasing Physical Activity Levels After School?” Research Quarterly for Exercise and Sport, 71(3): 240-248.

Datar, Ashlesha, and Roland Sturm. 2004. "Physical Education in Elementary School and Body Mass Index: Evidence from the Early Childhood Longitudinal Study.” American Journal of Public Health, 94(9): 1501-1506.

Ebbeling, Cara B., Dorota B. Pawlak, and David S. Ludwig. 2002. "Childhood Obesity: Public Health Crisis, Common Sense Cure." Lancet, 360: 473-482.

Grunbaum, Jo Anne et al. 2004. "Youth Risk Behavior Surveillance - United States, 2003.” Morbidity and Mortality Weekly Report, 53(SS-2): 1-29.

Hardin, J.W., H. Schmiediche, and R. J. Carroll. 2003. "Instrumental Variables, Bootstrapping, and Generalized Linear Models.” The STATA Journal, 3(4): 351360.

Hardman, K. and J. Marshall. 2000. World-wide Survey of the State and Status of School Physical Education. Report to the International Council for Sports Science and Physical Education. World wide web content: http://www.icsspe.org/portal/index.php?w=0\&z=2\&sta=2\&seite=project $/$ tx2170.h $\underline{\mathrm{tml}}$

Hedley, Allison A., C.L. Ogden, C.L. Johnson, M.D. Carroll, L.R. Curtin, and K.M. Flegal. 2004. "Prevalence of Overweight and Obesity Among US Children, Adolescents, and Adults, 1999-2004." Journal of the American Medical Association, 291(23): 2847-2850. 
Institute of Medicine. 2004. Preventing Childhood Obesity: Health in the Balance. (National Academies Press: Washington, D.C.).

Kahn, Emily B. et al. 2002. "The Effectiveness of Interventions to Increase Physical Activity: A Systematic Review.” American Journal of Preventive Medicine, 22(4S): 73-107.

Kimm, S.Y.S., and Obarzanek, E. 2002. "Childhood Obesity: A New Pandemic of the New Millennium." Pediatrics 110(5):1003-1007.

Lowry, R., N. Brener, S. Lee, J. Epping, J. Fulton, and D. Eaton. 2004. "Participation in High School Physical Education - United States, 1991-2003.” Morbidity and Mortality Weekly Report, 53(36): 844-847.

National Association of State Boards of Education. 2000. Fit, Healthy, and Ready to Learn: A School Health Policy Guide. Alexandria, VA: NASBE.

National Association for Sport \& Physical Education. 2002. 2001 Shape of the Nation Report. Reston, VA: AAHPERD.

National Association for Sport \& Physical Education. 2004. Physical Activity for Children: A Statement of Guidelines for Children Ages 5 - 12, 2nd Edition.

Ogden, Cynthia L., Katherine M. Flegal, Margaret D. Carroll, and Clifford L. Johnson. 2002. "Prevalence and Trends in Overweight Among US Children and Adolescents, 1999-2000." Journal of the American Medical Association, 288(14): 1728-1732.

Plankey, MW, Stevens, J, and PF Rust, "Prediction Equations Do Not Eliminate Systemic Error in Self-Reported Body Mass Index”, Obesity Research, 1997, 5(4): 308-314.

Plaza, Carla I. 2005. "School Nutrition and Physical Education Legislation: An Overview of 2005 State Activity.” NETSCAN Health Policy Tracking Service, April 4.

President's Council on Physical Fitness and Sports. 2001. "Physical Education Statement by the President's Council on Physical Fitness and Sports” NAS Newsletter, 16(1): 13.

Puhl, Rebecca, and Kelly D. Brownell. 2002. "Stigma, Discrimination, and Obesity." In C.G. Fairburn and K.D. Brownell (eds.), Eating Disorders and Obesity: A Comprehensive Handbook. Guilford Press: New York.

Simons-Morton, Bruce G., Wendell C. Taylor, Sharon A. Snider, and Iris W. Huang. 1993. "The Physical Activity of Fifth-Grade Students during Physical Education Classes.” American Journal of Public Health, 83(2): 262-264.

Sobal, Jeffery and Albert J. Stunkard. 1989. "Socioeconomic Status and Obesity: A Review of the Literature.” Psychological Bulletin, 105, 2: 260-275.

Staiger, D. and J.H. Stock. 1997. "Instrumental Variables Regression With Weak Instruments.” Econometrica, 65, 3: 557-586.

Strauss, Richard S. 2000. "Childhood Obesity and Self-Esteem." Pediatrics, 105(1): e15-e20.

Task Force on Community Preventive Services. 2001. "Increasing Physical Activity: A Report on Recommendations of the Task Force on Community Preventive Services.” Morbidity and Mortality Weekly Report, 50(RR-18): 1-16. 
Trudeau, Francois and Roy J. Shephard. 2005. "Contribution of School Programmes to Physical Activity Levels and Attitudes in Children and Adults.” Sports Medicine, 35(2): 89-105.

U.S. Department of Health and Human Services. 1996. Physical Activity and Health: A Report of the Surgeon General. Atlanta, GA: U.S. Department of Health and Human Services, Centers for Disease Control and Prevention, National Center for Chronic Disease Prevention and Health Promotion.

U.S. Department of Health and Human Services. 2000. Healthy People 2010:

Understanding and Improving Health, 2nd Edition. Washington D.C.: U.S. Government Printing Office.

U.S. Department of Health and Human Services. 2001. The Surgeon General's Call to Action to Prevent and Decrease Overweight and Obesity. Washington D.C.: U.S. Government Printing Office.

U. S. Department of Health and Human and the U.S. Department of Education. 2000. Promoting Better Health for Young People Through Physical Activity and Sports. Washington D.C.: U.S. Government Printing Office.

Villanueva, Elmer V., 2001, "The Validity of Self-reported Weight in US adults: A Population-based Cross-Sectional Study”, BMC public health, vol. 1 no. 11.

Wang, Guijing, and W.H. Dietz. 2002. "Economic Burden of Obesity in Youths Aged 6 to 17 Years: 1979-1999.” Pediatrics, 109(5): 81-86. 
Figure 1: Index of State PE Requirements

Viveast Strict

- Moderately Strict

- strict
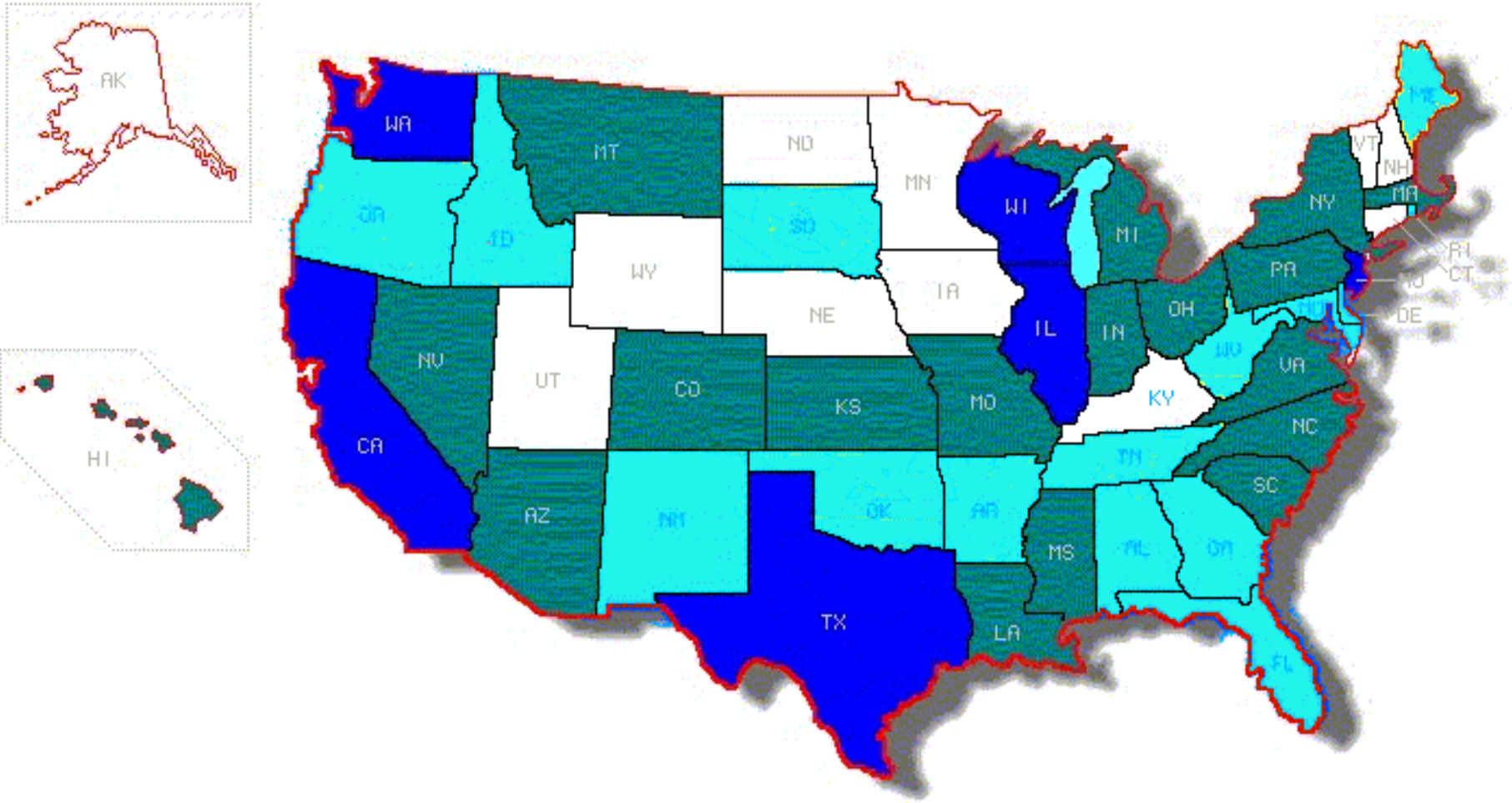

Note: The index is based on three binary variables: Whether the state has PE unit credit requirements exceeding 1 year, whether the state encourages compliance with PE standards, and whether the state required compliance with a PE curriculum in 2000 but not in 1994. These index components are nearly identical to the instrumental variables used in this paper; the only difference is that PE unit/credit requirement has been converted to a binary variable. States are colored according to the sum of these three variables (states that are colored white did not participate in the YRBSS). States shaded light (teal) had the least strict PE requirements, those shaded dark (blue) had the most strict PE requirements. 
Table 1: State Regulations Increase Minutes of PE Exercise Per Week First Stage of IV

\begin{tabular}{l|c}
\hline & Minutes of PE Exercise \\
Per Week (100s)
\end{tabular}

Note: The table lists regression coefficients and standard errors in brackets. 
Table 2: PE Exercise Increases Exercise and Strength Days, Decreases Activity Days Count Data Models

\begin{tabular}{|c|c|c|c|}
\hline & 1 & 2 & 3 \\
\hline & \multicolumn{2}{|c|}{ Days w. 20 Minutes Exercise } & Days w. Strength-Building \\
\hline & OLS & IV & OLS \\
\hline \multirow{4}{*}{$\begin{array}{l}\text { Minutes of PE Exercise } \\
\text { Per Week (100s) }\end{array}$} & 0.262 & 0.201 & 0.250 \\
\hline & {$[0.008]^{* *}$} & {$[0.071] * *$} & {$[0.011] * *$} \\
\hline & $\mathrm{ME}=0.941$ & $\mathrm{ME}=0.730$ & $\mathrm{ME}=0.729$ \\
\hline & {$[0.029]^{* *}$} & {$[0.277]^{* *}$} & {$[0.040]^{* *}$} \\
\hline \multirow[t]{2}{*}{ Age 15} & -0.007 & 0.002 & 0.032 \\
\hline & {$[0.013]$} & [0.019] & {$[0.026]$} \\
\hline \multirow[t]{2}{*}{ Age 16} & -0.051 & -0.057 & -0.003 \\
\hline & {$[0.014]^{* *}$} & {$[0.025]^{*}$} & [0.025] \\
\hline \multirow{2}{*}{ Age 17} & -0.104 & -0.121 & -0.07 \\
\hline & {$[0.015]^{* *}$} & {$[0.035]^{* *}$} & {$[0.032]^{*}$} \\
\hline \multirow[t]{2}{*}{ Age 18} & -0.152 & -0.161 & -0.094 \\
\hline & {$[0.016]^{* *}$} & {$[0.038]^{* *}$} & {$[0.032]^{* *}$} \\
\hline \multirow[t]{2}{*}{ Male } & 0.287 & 0.248 & 0.282 \\
\hline & {$[0.011]^{* *}$} & {$[0.018]^{* *}$} & {$[0.016]^{* *}$} \\
\hline \multirow[t]{2}{*}{ Black } & -0.167 & -0.146 & -0.148 \\
\hline & {$[0.016]^{* *}$} & {$[0.019] * *$} & {$[0.019] * *$} \\
\hline \multirow[t]{2}{*}{ Hispanic } & -0.147 & -0.141 & -0.069 \\
\hline & {$[0.016]^{* *}$} & {$[0.016]^{* *}$} & {$[0.018]^{* *}$} \\
\hline \multirow[t]{2}{*}{ Asian / Pacific Islander } & -0.17 & -0.141 & -0.046 \\
\hline & {$[0.024] * *$} & {$[0.026]^{* *}$} & {$[0.034]$} \\
\hline \multirow[t]{2}{*}{ Multiple/other race } & -0.015 & -0.024 & 0.047 \\
\hline & [0.017] & {$[0.026]$} & {$[0.033]$} \\
\hline \multirow[t]{2}{*}{ Northeast } & -0.067 & -0.092 & 0.000 \\
\hline & {$[0.030]^{*}$} & {$[0.033]^{* *}$} & {$[0.035]$} \\
\hline \multirow[t]{2}{*}{ Midwest } & -0.009 & -0.038 & -0.006 \\
\hline & {$[0.020]$} & {$[0.022]$} & {$[0.032]$} \\
\hline \multirow[t]{2}{*}{ South } & -0.061 & -0.095 & -0.084 \\
\hline & {$[0.019]^{* *}$} & {$[0.021]^{* *}$} & {$[0.031]^{* *}$} \\
\hline \multirow[t]{2}{*}{ Urban } & -0.01 & -0.017 & -0.002 \\
\hline & {$[0.014]$} & {$[0.016]$} & [0.019] \\
\hline \multirow[t]{2}{*}{2001} & -0.087 & -0.047 & -0.034 \\
\hline & {$[0.014]^{* *}$} & {$[0.023]^{*}$} & {$[0.024]$} \\
\hline \multirow[t]{2}{*}{2003} & -0.098 & -0.076 & -0.061 \\
\hline & {$[0.016]^{* *}$} & {$[0.023]^{* *}$} & {$[0.030]^{*}$} \\
\hline \multirow[t]{2}{*}{ State Per Capita Income } & 0.001 & -0.004 & -0.001 \\
\hline & [0.004] & {$[0.005]$} & {$[0.006]$} \\
\hline \multirow{2}{*}{$\begin{array}{l}\text { State Percentage with } \\
\text { Bachelor's Degree }\end{array}$} & 0.002 & 0.006 & -0.004 \\
\hline & [0.003] & {$[0.004]$} & {$[0.004]$} \\
\hline \multirow{2}{*}{$\begin{array}{l}\text { National School Lunch } \\
\text { Participation Per Capita }\end{array}$} & -0.17 & 0.351 & -0.202 \\
\hline & [0.457] & [0.541] & [0.677] \\
\hline \multirow{2}{*}{ Constant } & 1.115 & 1.194 & 1.031 \\
\hline & {$[0.111]^{* *}$} & {$[0.141]^{* *}$} & {$[0.157]^{* *}$} \\
\hline Number of Obs. & 36888 & 36888 & 36888 \\
\hline
\end{tabular}


Table 2 Continued

\begin{tabular}{|c|c|c|c|}
\hline & 4 & 5 & 6 \\
\hline \multirow{6}{*}{$\begin{array}{l}\text { Minutes of PE Exercise } \\
\text { Per Week (100s) }\end{array}$} & Days w. Strength-Building & \multicolumn{2}{|c|}{ Days w. 30 Minutes Light Activity } \\
\hline & IV & OLS & IV \\
\hline & 0.240 & 0.151 & -0.256 \\
\hline & {$[0.078]^{* *}$} & {$[0.010]^{* *}$} & {$[0.095]^{* *}$} \\
\hline & $\mathrm{ME}=0.715$ & $\mathrm{ME}=0.378$ & $\mathrm{ME}=-0.653$ \\
\hline & {$[0.304]^{* *}$} & {$[0.037]^{* *}$} & {$[0.370]^{*}$} \\
\hline \multirow{2}{*}{ Age 15} & 0.042 & 0.031 & 0.013 \\
\hline & {$[0.025]$} & [0.031] & {$[0.030]$} \\
\hline \multirow[t]{2}{*}{ Age 16} & 0.007 & 0.03 & -0.071 \\
\hline & {$[0.032]$} & {$[0.030]$} & {$[0.038]$} \\
\hline \multirow{2}{*}{ Age 17} & -0.059 & 0.02 & -0.145 \\
\hline & {$[0.045]$} & [0.029] & {$[0.050]^{* *}$} \\
\hline \multirow[t]{2}{*}{ Age 18} & -0.085 & 0.005 & -0.169 \\
\hline & [0.047] & [0.035] & {$[0.053]^{* *}$} \\
\hline \multirow[t]{2}{*}{ Male } & 0.279 & 0.08 & 0.170 \\
\hline & {$[0.024]^{* *}$} & {$[0.016]^{* *}$} & {$[0.028]^{* *}$} \\
\hline \multirow[t]{2}{*}{ Black } & -0.142 & -0.228 & -0.192 \\
\hline & {$[0.023]^{* *}$} & {$[0.031]^{* *}$} & {$[0.028]^{* *}$} \\
\hline \multirow[t]{2}{*}{ Hispanic } & -0.055 & -0.243 & -0.204 \\
\hline & {$[0.020]^{* *}$} & {$[0.026]^{* *}$} & {$[0.026]^{* *}$} \\
\hline \multirow[t]{2}{*}{ Asian / Pacific Islander } & -0.041 & -0.177 & -0.166 \\
\hline & [0.031] & {$[0.040]^{* *}$} & {$[0.040]^{* *}$} \\
\hline \multirow[t]{2}{*}{ Multiple/other race } & 0.048 & -0.037 & -0.018 \\
\hline & [0.031] & [0.038] & [0.039] \\
\hline \multirow[t]{2}{*}{ Northeast } & -0.004 & -0.061 & -0.095 \\
\hline & {$[0.033]$} & [0.038] & {$[0.047]^{*}$} \\
\hline \multirow[t]{2}{*}{ Midwest } & -0.006 & -0.094 & -0.118 \\
\hline & [0.028] & {$[0.024]^{* *}$} & {$[0.035]^{* *}$} \\
\hline \multirow[t]{2}{*}{ South } & -0.076 & -0.124 & -0.137 \\
\hline & {$[0.025]^{* *}$} & {$[0.030]^{* *}$} & {$[0.033]^{* *}$} \\
\hline \multirow[t]{2}{*}{ Urban } & -0.004 & 0.001 & -0.028 \\
\hline & {$[0.016]$} & {$[0.025]$} & {$[0.028]$} \\
\hline \multirow[t]{2}{*}{2001} & -0.031 & -0.036 & 0.058 \\
\hline & {$[0.026]$} & {$[0.020]$} & {$[0.033]$} \\
\hline \multirow[t]{2}{*}{2003} & -0.054 & -0.052 & 0.025 \\
\hline & {$[0.026]^{*}$} & {$[0.025]^{*}$} & [0.034] \\
\hline \multirow[t]{2}{*}{ State Per Capita Income } & -0.002 & -0.002 & 0.003 \\
\hline & [0.005] & {$[0.006]$} & [0.007] \\
\hline \multirow{2}{*}{$\begin{array}{l}\text { State Percentage with } \\
\text { Bachelor's Degree }\end{array}$} & -0.004 & 0.000 & 0.007 \\
\hline & [0.004] & [0.004] & [0.005] \\
\hline \multirow{2}{*}{$\begin{array}{l}\text { National School Lunch } \\
\text { Participation Per Capita }\end{array}$} & -0.175 & -0.326 & -0.041 \\
\hline & {$[0.583]$} & {$[0.717]$} & {$[0.710]$} \\
\hline \multirow[t]{2}{*}{ Constant } & 1.061 & 1.065 & 0.992 \\
\hline & {$[0.147]^{* *}$} & {$[0.163]^{* *}$} & {$[0.187]^{* *}$} \\
\hline Number of Obs. & 36888 & 36888 & 36888 \\
\hline
\end{tabular}

Note: The table lists regression coefficients and standard errors in brackets. For Minutes of PE Exercise Per Week, the marginal effect and its standard error are also listed. 
Table 3: PE Exercise Time Has No Measurable Impact on BMI OLS and IV Models

\begin{tabular}{|c|c|c|}
\hline & 1 & 2 \\
\hline & BMI & BMI \\
\hline & OLS & IV \\
\hline \multirow{2}{*}{$\begin{array}{l}\text { Minutes of PE Exercise } \\
\text { Per Week (100s) }\end{array}$} & 0.019 & 0.148 \\
\hline & {$[0.047]$} & {$[0.494]$} \\
\hline \multirow[t]{2}{*}{ Age 15} & 0.383 & 0.390 \\
\hline & {$[0.126]^{* *}$} & {$[0.122]^{* *}$} \\
\hline \multirow[t]{2}{*}{ Age 16} & 0.563 & 0.596 \\
\hline & {$[0.103]^{* *}$} & {$[0.149]^{* *}$} \\
\hline \multirow{2}{*}{ Age 17} & 0.836 & 0.890 \\
\hline & {$[0.138]^{* *}$} & {$[0.234]^{* *}$} \\
\hline \multirow[t]{2}{*}{ Age 18} & 0.895 & 0.952 \\
\hline & {$[0.149]^{* *}$} & {$[0.261]^{* *}$} \\
\hline \multirow[t]{2}{*}{ Male } & 0.762 & 0.733 \\
\hline & {$[0.083]^{* *}$} & {$[0.170]^{* *}$} \\
\hline \multirow{2}{*}{ Black } & 1.129 & 1.120 \\
\hline & {$[0.151]^{* *}$} & {$[0.152]^{* *}$} \\
\hline \multirow[t]{2}{*}{ Hispanic } & 0.853 & 0.843 \\
\hline & {$[0.118]^{* *}$} & {$[0.117]^{* *}$} \\
\hline \multirow{2}{*}{ Asian / Pacific Islander } & -0.352 & -0.355 \\
\hline & {$[0.205]$} & [0.198] \\
\hline \multirow[t]{2}{*}{ Multiple/other race } & 0.421 & 0.416 \\
\hline & [0.183]* & [0.176]* \\
\hline \multirow[t]{2}{*}{ Northeast } & 0.383 & 0.393 \\
\hline & {$[0.160]^{*}$} & [0.177]* \\
\hline \multirow[t]{2}{*}{ Midwest } & 0.423 & 0.429 \\
\hline & {$[0.165]^{*}$} & {$[0.167]^{*}$} \\
\hline \multirow[t]{2}{*}{ South } & 0.525 & 0.529 \\
\hline & {$[0.148]^{* *}$} & {$[0.146]^{* *}$} \\
\hline \multirow[t]{2}{*}{ Urban } & 0.135 & 0.145 \\
\hline & [0.087] & [0.096] \\
\hline \multirow[t]{2}{*}{2001} & -0.096 & -0.125 \\
\hline & [0.112] & {$[0.116]$} \\
\hline \multirow[t]{2}{*}{2003} & 0.342 & 0.319 \\
\hline & {$[0.122]^{* *}$} & {$[0.151]^{*}$} \\
\hline \multirow{2}{*}{ State Per Capita Income } & -0.004 & -0.006 \\
\hline & [0.030] & [0.032] \\
\hline \multirow{2}{*}{$\begin{array}{l}\text { State Percentage with } \\
\text { Bachelor's Degree }\end{array}$} & -0.038 & -0.040 \\
\hline & [0.031] & [0.028] \\
\hline \multirow{2}{*}{$\begin{array}{l}\text { National School Lunch } \\
\text { Participation Per Capita }\end{array}$} & -2.537 & -2.638 \\
\hline & [2.935] & [3.006] \\
\hline \multirow[t]{2}{*}{ Constant } & 22.632 & 22.659 \\
\hline & {$[0.699]^{* *}$} & {$[0.713]^{* *}$} \\
\hline Number of Obs. & 36888 & 36888 \\
\hline R-squared & .03 & \\
\hline
\end{tabular}

Note: The table lists regression coefficients and standard errors in brackets. 


\section{Table 4: PE Exercise Time Has No Measurable Impact on Weight Classification Logit and Logit IV Models}

\begin{tabular}{|c|c|c|c|c|}
\hline & 1 & 2 & 3 & 4 \\
\hline & $\begin{array}{c}\text { Overweight } \\
(>=95 \text { th \% ile) }\end{array}$ & $\begin{array}{c}\text { Overweight } \\
\text { (>=95th \% ile) }\end{array}$ & $\begin{array}{c}\text { Risk of } \\
\text { Overweight } \\
\text { (>=85th \% ile) }\end{array}$ & $\begin{array}{c}\text { Risk of } \\
\text { Overweight } \\
\text { (>=85th \% ile) }\end{array}$ \\
\hline & OLS & IV & OLS & IV \\
\hline \multirow{4}{*}{ Minutes of PE Exercise Per Week (100s) } & -0.012 & 0.076 & -0.008 & 0.073 \\
\hline & {$[0.028]$} & [0.338] & [0.024] & [0.239] \\
\hline & $\mathrm{ME}=-0.001$ & $\mathrm{ME}=0.008$ & $\mathrm{ME}=-0.001$ & $\mathrm{ME}=0.014$ \\
\hline & {$[0.003]$} & {$[0.033]$} & [0.005] & {$[0.045]$} \\
\hline \multirow[t]{2}{*}{ Age 15} & -0.263 & -0.258 & -0.169 & -0.165 \\
\hline & {$[0.086]^{* *}$} & {$[0.089]^{* *}$} & {$[0.063]^{* *}$} & {$[0.066]^{*}$} \\
\hline \multirow[t]{2}{*}{ Age 16} & -0.391 & -0.369 & -0.311 & -0.291 \\
\hline & {$[0.085]^{* *}$} & {$[0.123]^{* *}$} & {$[0.057]^{* *}$} & {$[0.086]^{* *}$} \\
\hline \multirow[t]{2}{*}{ Age 17} & -0.414 & -0.378 & -0.422 & -0.389 \\
\hline & {$[0.110]^{* *}$} & {$[0.169]^{*}$} & {$[0.077]^{* *}$} & {$[0.122]^{* *}$} \\
\hline \multirow[t]{2}{*}{ Age 18} & -0.65 & -0.611 & -0.57 & -0.535 \\
\hline & {$[0.132]^{* *}$} & {$[0.211]^{* *}$} & {$[0.072]^{* *}$} & {$[0.131]^{* *}$} \\
\hline \multirow[t]{2}{*}{ Male } & 0.546 & 0.526 & 0.38 & 0.362 \\
\hline & {$[0.058]^{* *}$} & {$[0.107]^{* *}$} & {$[0.041]^{* *}$} & {$[0.073]^{* *}$} \\
\hline \multirow[t]{2}{*}{ Black } & 0.311 & 0.304 & 0.457 & 0.451 \\
\hline & {$[0.100]^{* *}$} & {$[0.078]^{* *}$} & {$[0.073]^{* *}$} & {$[0.063]^{* *}$} \\
\hline \multirow[t]{2}{*}{ Hispanic } & 0.367 & 0.360 & 0.37 & 0.364 \\
\hline & {$[0.080]^{* *}$} & {$[0.075]^{* *}$} & {$[0.062]^{* *}$} & {$[0.054]^{* *}$} \\
\hline \multirow[t]{2}{*}{ Asian / Pacific Islander } & -0.152 & -0.155 & -0.114 & -0.117 \\
\hline & {$[0.160]$} & [0.134] & {$[0.112]$} & [0.099] \\
\hline \multirow[t]{2}{*}{ Multiple/other race } & 0.243 & 0.239 & 0.132 & 0.129 \\
\hline & [0.161] & {$[0.130]$} & [0.086] & {$[0.086]$} \\
\hline \multirow[t]{2}{*}{ Northeast } & 0.117 & 0.124 & 0.11 & 0.116 \\
\hline & [0.143] & [0.128] & [0.095] & [0.095] \\
\hline \multirow[t]{2}{*}{ Midwest } & 0.325 & 0.330 & 0.106 & 0.111 \\
\hline & {$[0.117]^{* *}$} & {$[0.109]^{* *}$} & [0.081] & [0.082] \\
\hline \multirow[t]{2}{*}{ South } & 0.373 & 0.376 & 0.182 & 0.185 \\
\hline & {$[0.101]^{* *}$} & {$[0.093]^{* *}$} & [0.077]* & {$[0.072]^{* *}$} \\
\hline \multirow[t]{2}{*}{ Urban } & 0.09 & 0.097 & 0.081 & 0.087 \\
\hline & [0.055] & {$[0.055]$} & {$[0.051]$} & {$[0.050]$} \\
\hline \multirow[t]{2}{*}{2001} & -0.029 & -0.050 & -0.042 & -0.061 \\
\hline & {$[0.080]$} & [0.097] & [0.059] & {$[0.071]$} \\
\hline \multirow[t]{2}{*}{2003} & 0.176 & 0.159 & 0.193 & 0.178 \\
\hline & {$[0.088]^{*}$} & [0.102] & {$[0.058]^{* *}$} & [0.075]* \\
\hline \multirow[t]{2}{*}{ State Per Capita Income } & 0.007 & 0.006 & 0.003 & 0.002 \\
\hline & [0.021] & {$[0.020]$} & [0.014] & {$[0.016]$} \\
\hline \multirow[t]{2}{*}{ State Percentage with Bachelor's Degree } & -0.016 & -0.017 & -0.019 & -0.021 \\
\hline & [0.019] & {$[0.017]$} & {$[0.014]$} & {$[0.014]$} \\
\hline \multirow[t]{2}{*}{ National School Lunch Participation Per Capita } & 0.191 & 0.111 & -0.983 & -1.052 \\
\hline & [2.238] & [2.044] & [1.469] & [1.497] \\
\hline \multirow[t]{2}{*}{ Constant } & -2.296 & -2.278 & -0.783 & -0.766 \\
\hline & {$[0.547]^{* *}$} & {$[0.514]^{* *}$} & [0.401] & [0.398] \\
\hline Number of Obs. & 36888 & 36888 & 36888 & 36888 \\
\hline
\end{tabular}

Note: The table lists regression coefficients and standard errors in brackets. For Minutes of PE Exercise Per Week, the marginal effect and its standard error are also listed. 


\section{Appendix Table 1:}

Summary Statistics

$\mathrm{N}=36,888$

\begin{tabular}{|c|c|c|c|c|c|}
\hline & Mean & S.D. & Minimum & Median & Maximum \\
\hline BMI & 23.30 & 4.79 & 8.82 & 22.18 & 91.11 \\
\hline Overweight & 0.12 & 0.33 & 0.00 & 0.00 & 1.00 \\
\hline Risk of Overweight & 0.28 & 0.45 & 0.00 & 0.00 & 1.00 \\
\hline Days w. 20 Minutes Exercise & 3.57 & 2.52 & 0.00 & 4.00 & 7.00 \\
\hline $\begin{array}{l}\text { Days w. Strength-Building } \\
\text { Activity }\end{array}$ & 2.89 & 2.48 & 0.00 & 3.00 & 7.00 \\
\hline $\begin{array}{l}\text { Days w. } 30 \text { Minutes Light } \\
\text { Activity }\end{array}$ & 2.49 & 2.48 & 0.00 & 2.00 & 7.00 \\
\hline $\begin{array}{l}\text { Minutes of PE Exercise Per } \\
\text { Week (100s) }\end{array}$ & 0.65 & 0.86 & 0.00 & 0.10 & 3.00 \\
\hline $\begin{array}{l}\text { State curriculum required in } \\
2000 \text { but not } 1994\end{array}$ & 0.23 & 0.42 & 0.00 & 0.00 & 1.00 \\
\hline $\mathrm{PE}$ unit/credit requirement & 1.22 & 0.80 & 0.00 & 1.00 & 4.00 \\
\hline State encourages compliance & 0.44 & 0.50 & 0.00 & 0.00 & 1.00 \\
\hline Age $<=14$ & 0.09 & 0.29 & 0.00 & 0.00 & 1.00 \\
\hline Age 15 & 0.22 & 0.42 & 0.00 & 0.00 & 1.00 \\
\hline Age 16 & 0.26 & 0.44 & 0.00 & 0.00 & 1.00 \\
\hline Age 17 & 0.26 & 0.44 & 0.00 & 0.00 & 1.00 \\
\hline Age 18 & 0.17 & 0.37 & 0.00 & 0.00 & 1.00 \\
\hline Male & 0.49 & 0.50 & 0.00 & 0.00 & 1.00 \\
\hline Female & 0.51 & 0.50 & 0.00 & 1.00 & 1.00 \\
\hline White & 0.43 & 0.49 & 0.00 & 0.00 & 1.00 \\
\hline Black & 0.23 & 0.42 & 0.00 & 0.00 & 1.00 \\
\hline Hispanic & 0.23 & 0.42 & 0.00 & 0.00 & 1.00 \\
\hline Asian / Pacific Islander & 0.04 & 0.19 & 0.00 & 0.00 & 1.00 \\
\hline Multiple/other race & 0.07 & 0.25 & 0.00 & 0.00 & 1.00 \\
\hline Northeast & 0.11 & 0.31 & 0.00 & 0.00 & 1.00 \\
\hline Midwest & 0.16 & 0.37 & 0.00 & 0.00 & 1.00 \\
\hline West & 0.22 & 0.41 & 0.00 & 0.00 & 1.00 \\
\hline South & 0.52 & 0.50 & 0.00 & 0.00 & 1.00 \\
\hline Urban & 0.42 & 0.49 & 0.00 & 0.00 & 1.00 \\
\hline Suburban & 0.45 & 0.50 & 0.00 & 0.00 & 1.00 \\
\hline Rural & 0.13 & 0.33 & 0.00 & 0.00 & 1.00 \\
\hline 1999 & 0.36 & 0.48 & 0.00 & 0.00 & 1.00 \\
\hline 2001 & 0.30 & 0.46 & 0.00 & 0.00 & 1.00 \\
\hline 2003 & 0.33 & 0.47 & 0.00 & 0.00 & 1.00 \\
\hline $\begin{array}{l}\text { State Per Capita Income } \\
\text { (1000s of } 2003 \text { USD) }\end{array}$ & 30.45 & 3.49 & 22.50 & 29.94 & 40.43 \\
\hline $\begin{array}{l}\text { State Percentage with } \\
\text { Bachelor’s Degree }\end{array}$ & 25.25 & 3.59 & 15.80 & 24.60 & 37.60 \\
\hline $\begin{array}{l}\text { National School Lunch } \\
\text { Participation Per Capita }\end{array}$ & 0.10 & 0.02 & 0.06 & 0.10 & 0.15 \\
\hline
\end{tabular}

Note: Data are from the Youth Risk Behavior Surveillance System (1999, 2001, 2003), Shape of the Nation Report (2001), and the School Health Policies and Programs Study (1994, 2000). 